\title{
Osseous erosion by herniated nucleus pulposus mimicking intraspinal tumor: a case report
}

\author{
Shinji Yoshioka • Koichi Sairyo • Toshinori Sakai • \\ Tatsuya Tamura $\cdot$ Hirofumi Kosaka • \\ Natsuo Yasui
}

Received: 24 November 2009/ Accepted: 1 November 2010/Published online: 20 November 2010

(C) The Author(s) 2010. This article is published with open access at Springerlink.com

\begin{abstract}
Erosion of spinal osseous structure, so-called scalloping, has been rarely reported associated with herniated nucleus pulposus (HNP). We report a rare case of HNP causing erosion of the spinal osseous structure (including lamina). The patient was an 81-year-old woman with 3-year history of low-back pain and left leg radiating pain. Muscle weakness of the left leg was also apparent. Computed tomography following myelography showed severe compression of the dural sac at the level of L3-L4; furthermore, erosion of the lamina, pedicle, and vertebral body was noted, indicating that the space-occupying mass was most probably a tumorous lesion. The mass also showed calcification inside. During the surgery, the mass was confirmed to be an HNP with calcification. Following resection, the pain disappeared. Surgeons should be aware of the possibility of scalloping of the vertebrae caused by HNP mimicking a tumorous lesion.
\end{abstract}

Keywords Herniated nucleus pulposus - Scalloping · Erosion

S. Yoshioka - K. Sairyo - T. Sakai · T. Tamura · H. Kosaka · N. Yasui

Department of Orthopedics, Institute of Health Biosciences, The University of Tokushima Graduate School, Tokushima, Japan

K. Sairyo $(\square)$

Department of Orthopedic Surgery,

Teikyo University Mizonokuchi Hospital,

3-8-3 Mizonokuchi, Takatsu-ku, Kawasaki 213-8507, Japan

e-mail: sairyokun@hotmail.com

\section{Introduction}

Increased intraspinal pressure exerted by an expanding mass such as a slow-growing intraspinal tumor is a common cause of erosion (scalloping) of the posterior vertebral wall [1-8]. As for other causes of scalloping, communicating hydrocephalus, Marfan syndrome, Ehlers-Danlos syndrome, ankylosing spondylitis, neurofibromatosis, achondroplasia, Morquio syndrome, Hurler syndrome, acromegaly, tuberculosis, and fungal infections have been reported [4, 8-15]. Erosion of the spinal osseous structure by herniated nucleus pulposus (HNP) has rarely been reported. Only $10 \mathrm{HNP}$ cases with scalloping have been reported in the pertinent English-language literature [16-20].

We describe an uncommon case of HNP causing erosion of the vertebral body, the pedicle, and the lamina, which was initially diagnosed to be a tumorous lesion located in the spinal canal.

\section{Case report}

The patient was an 81-year-old woman with 3-year history of low-back pain and left leg radiating pain. Her symptoms had gradually worsened until she was not able to walk unaided. Finally, she was referred to our hospital for surgical intervention.

Neurological examination showed a positive straight-leg raising test at $20^{\circ}$ and positive femoral nerve stretching testing on the left side. Muscle weakness found in the left quadriceps was 4-/5, and that of the left tibialis anterior was $4 / 5$. Hypoesthesia was noted in the left leg at the L4 area.

Plain AP and lateral radiographs of the lumbar spine are shown in Fig. 1. There was no spinal abnormality except 
Fig. 1 Plain AP and lateral radiographs of the lumbar spine
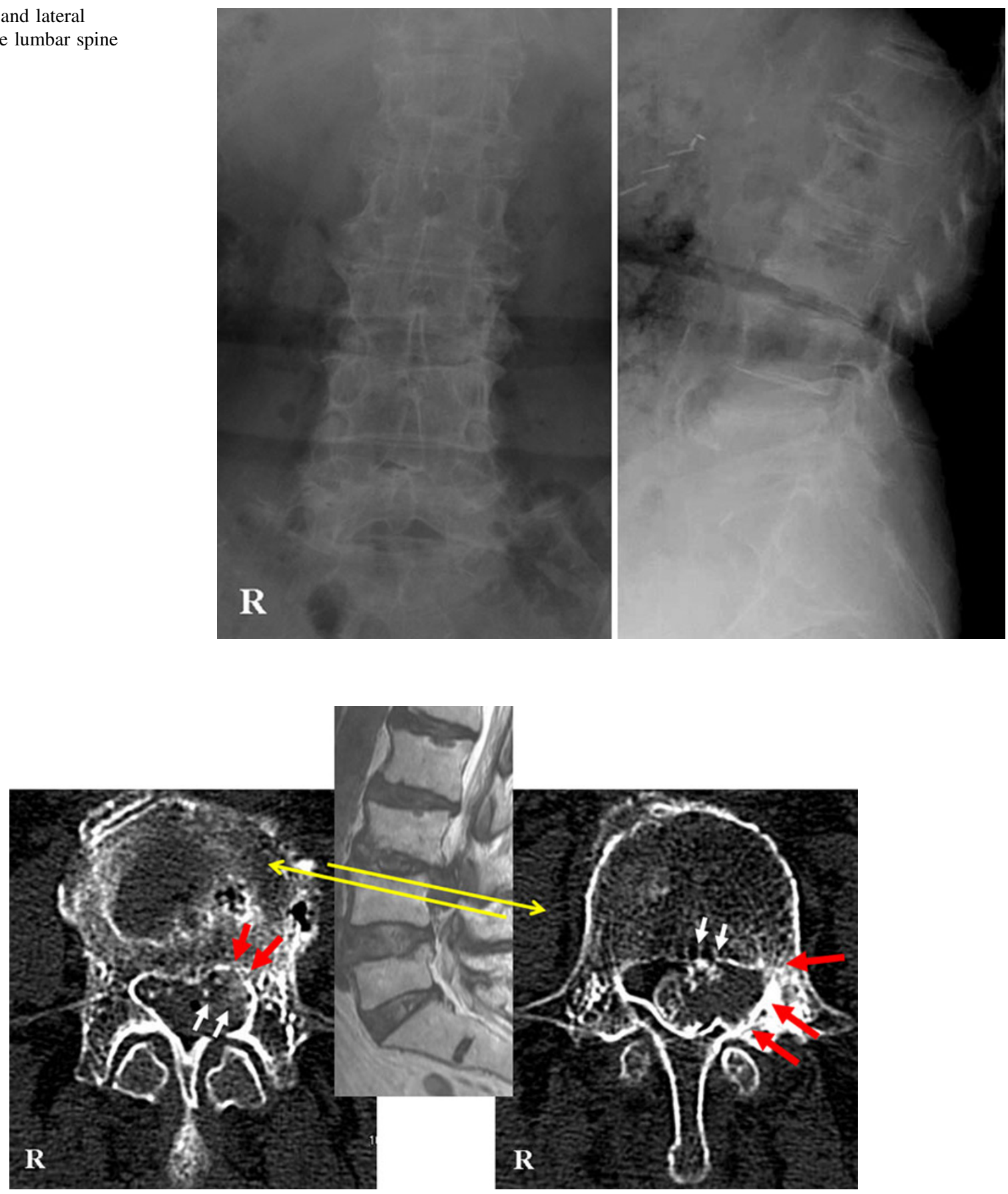

Fig. 2 CT myelography following myelography at L3-L4 showing a tumorous mass with partial calcification in the spinal canal. The right panel shows the slice corresponding to the cranial aspect of the L4

for osteoporosis (Fig. 1). Dual-energy X-ray absorptiometry (DXA) demonstrated an L2-L4 T-score of -2.5 . Computed tomographic (CT) myelography following myelography at L3-L4 showed a tumorous mass with partial calcification in the spinal canal, and erosion of the adjacent L4 vertebral body, pedicle, and lamina. These findings suggested an intraspinal tumorous lesion (Fig. 2). The right panel in Fig. 2 shows the slice corresponding to pedicle. The left panel shows the slice corresponding to the caudal aspect of the L4 pedicle. Red arrows indicate the location of scalloping, and white arrows, the calcification in the mass

the cranial aspect of the L4 pedicle, and the left panel shows the one corresponding to the caudal aspect of the L4 pedicle. Red arrows indicate the location of scalloping, and white arrows, the calcification in the mass.

Magnetic resonance (MR) sagittal images showed a mass at L3-L4 (Fig. 3a). The mass extended caudally and strongly compressed the dural sac. Axial MR images showed that the mass was located on the right side and 

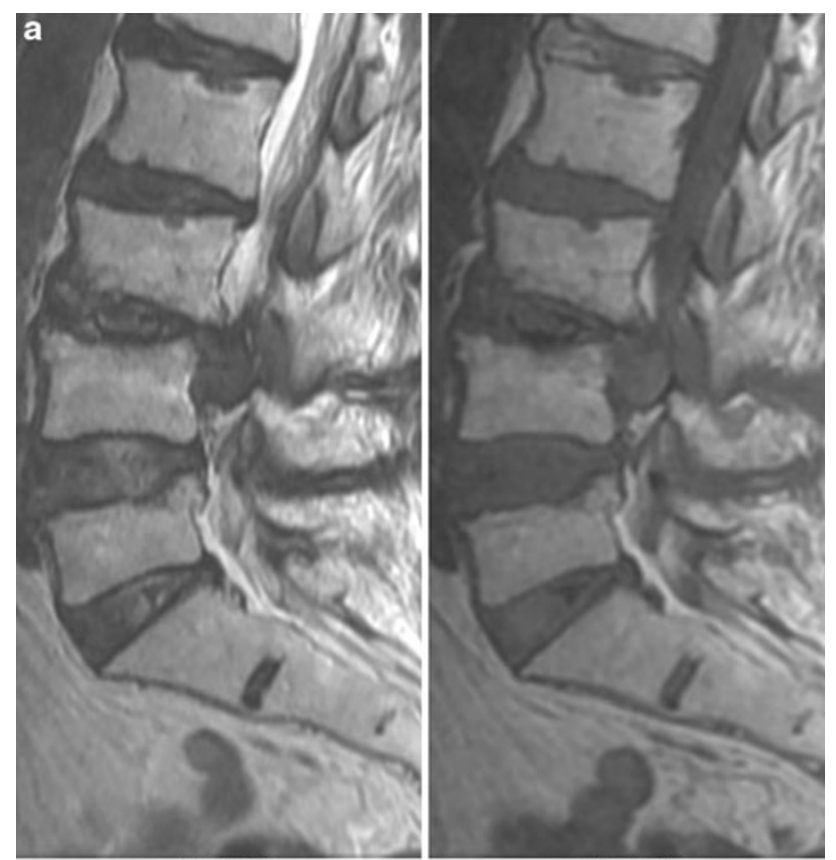

T2-WI

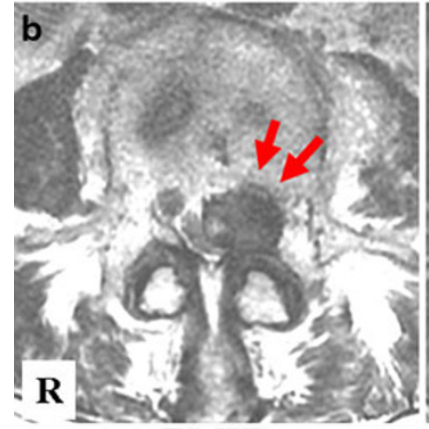

T2-WI

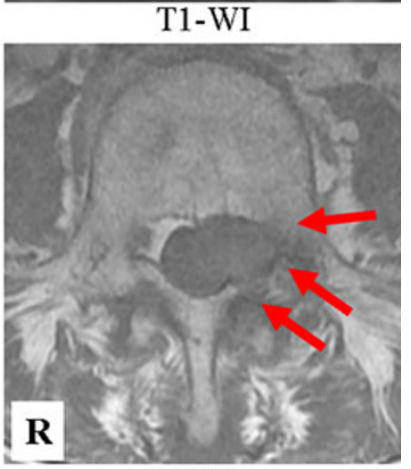

T1-WI

Fig. 3 a MR sagittal images showing a mass at L3-L4. The mass extended caudally and strongly compressed the dural sac. b Axial MR images showing the mass located on the right side and the scalloping (red arrows)

caused scalloping (Fig. 3b). Arrows in Fig. 3b indicate the location of scalloping.

Because of the long clinical history and the MR images, we considered the tumor to be not malignant, but rather most likely to be an HNP, and therefore did not perform biopsy prior to removing it. However, we should have done a biopsy for differential diagnosis of slow-growing malignant tumors to ensure safer treatment.

L4 hemilaminectomy was required to remove the entire mass from the spinal canal. A voluminous calcified mass was found beneath the left L4 nerve root. The L4 nerve root was displaced laterally, adhered to the mass. The mass partially contained calcified tissue. After removal of the mass, erosion of the vertebral body was noted. Figure 4 shows the removed tissue 3 days after fixation in $10 \%$ formic acid. Apparently, it was not a tumor, but HNP

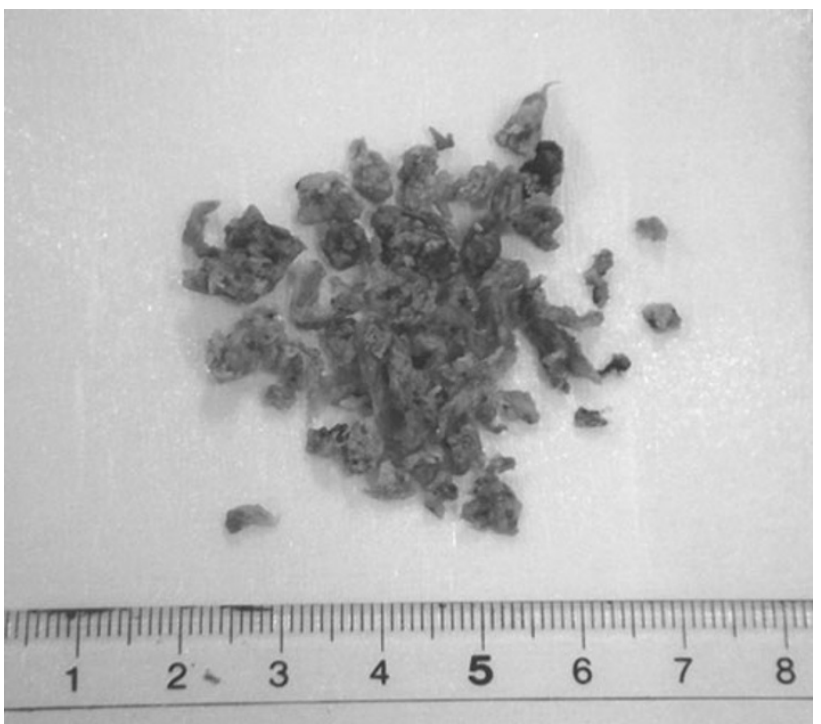

Fig. 4 The surgical specimen shown after fixation in $10 \%$ formic acid. On macroscopic examination, it seems to be an HNP

tissue. Histopathological findings were consistent with those of calcified HNP. Postoperative MR images revealed that the thecal sac was totally decompressed (Fig. 5). Scalloping was also clearly seen on postoperative MRI (arrows in the right panel). Postoperatively, her leg pain subsided, but muscle weakness remained. The patient was asked whether data concerning her case could be submitted for publication, and she consented.

\section{Discussion}

It is well known that increased intraspinal pressure exerted by an expanding mass such as an intraspinal tumorous lesion may cause erosion (scalloping) of the spinal osseous structures. Ependymoma, dermoid cysts, epidermoid cysts, schwannoma, lipomas, and lymphomas frequently show thinning of laminae and pedicles [4, 7, 8, 20]. Dural ectasia, associated with inherited disorders such as Marfan syndrome, and Ehlers-Danlos syndrome, and neurofibromatosis is also a cause of scalloping of vertebral bodies [4, 8, 9, $11,12,15]$. There have been few reports, however, of scalloping of the spinal osseous structures caused by HNP.

The present case showed erosion of the L4 vertebral body, pedicle, and lamina by a calcified herniated mass of the L3-L4 intervertebral disc. There have been 10 cases of bone erosion due to HNP reported in the literature [16-20]. Most cases showed erosion in the posterior wall of the vertebral bodies (Table 1). Vadala et al. [20] stated that thinning of the laminae and pedicles was commonly seen associated with a tumorous lesion, and that this kind of scalloping was not observed in cases with HNP. An HNP 
Fig. 5 Postoperative MR images revealed that the thecal sac was totally decompressed. Scalloping was also clearly seen on postoperative MRI (arrows in the right panel)

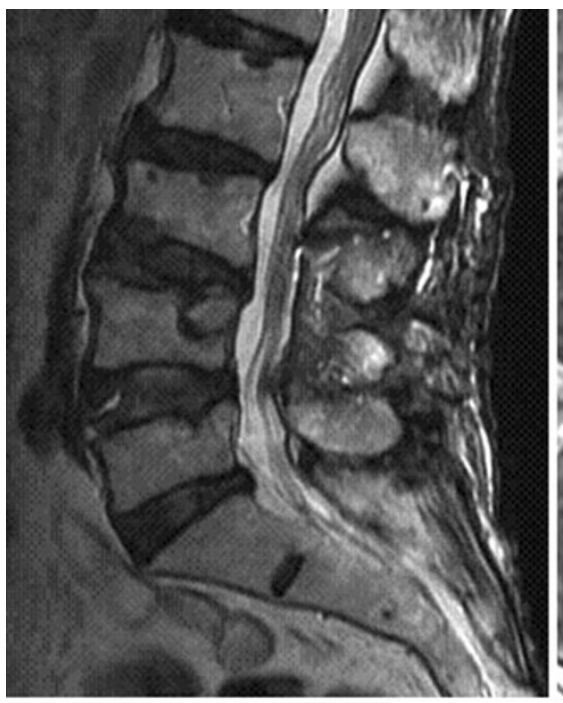

Mid-sagittal T2-WI

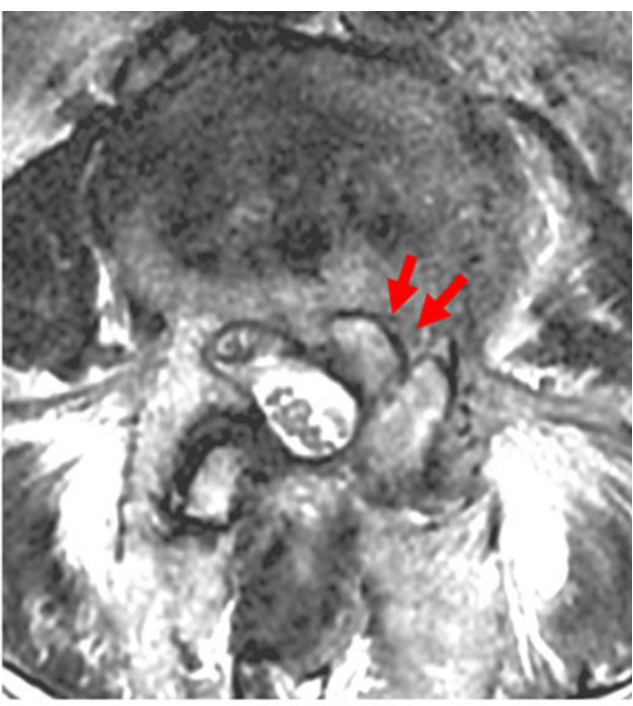

Axial T2-WI

Table 1 Summary of the characteristics of previous cases

\begin{tabular}{|c|c|c|c|c|c|c|}
\hline Case & Authors & $\begin{array}{l}\text { Sex, age } \\
\text { (years) }\end{array}$ & Clinical history & $\begin{array}{l}\text { Location of } \\
\text { herniation }\end{array}$ & $\begin{array}{l}\text { Location of } \\
\text { scalloping }\end{array}$ & Calcification \\
\hline 1 & \multirow[t]{4}{*}{ Vadala et al. [20] } & Female, 39 & More than 1 year & L5 & Vertebral body & - \\
\hline 2 & & Male, 45 & 7 years & L5 & Vertebral body & - \\
\hline 3 & & Male, 41 & Several years & $\mathrm{L} 5 / \mathrm{S}$ & Vertebral body & - \\
\hline 4 & & Female, 55 & 3 years & L5 & Vertebral body & - \\
\hline 5 & \multirow[t]{3}{*}{ Norfray et al. [19] } & Female, 43 & 3 years & $\mathrm{S} 1$ & Vertebral body & - \\
\hline 6 & & Male, 48 & 7 years & L4 & Neural foramen & - \\
\hline 7 & & Male, 41 & 3 years & L5 & Vertebral body & + \\
\hline 8 & Briceno et al. [17] & Male, 46 & 19 years & L4 & Vertebral body and pedicle & - \\
\hline 9 & Flak et al. [18] & Male, 28 & 1.5 years & $\mathrm{S} 1$ & Vertebral body & + \\
\hline 10 & Berthelot et al. [16] & Male, 61 & Several weeks & $\mathrm{T} 10$ & Vertebral body & + \\
\hline Present case & Yoshioka et al. & Female, 82 & 3 years & L4 & Vertebral body, pedicle, and lamina & + \\
\hline
\end{tabular}

would usually cause scalloping of the vertebral bodies only, if there were any [20]. In the present case, erosive change occurred in the lamina as well as the vertebral body. No previous report showed such wide erosion of the spinal osseous structure by HNP as shown in the present case.

Several authors have advocated that long clinical history of pain and chronic pressure due to large-size HNP could cause bone erosion [16-20]. Nine of the 11 cases reported so far, including the present case, had history of pain longer than 1 year (Table 1). Vadala et al. [20] also suggested that old HNPs might cause a mechanical irritating action on the small vascular structures of the bone cortex. Additionally, our patient was an 81-year-old woman with overt osteoporosis. We supposed that an elderly patient with osteoporosis suffering for a long period from pain caused by an HNP was likely to show erosion of spinal osseous structures.

\section{Conflict of interest None.}

Open Access This article is distributed under the terms of the Creative Commons Attribution Noncommercial License which permits any noncommercial use, distribution, and reproduction in any medium, provided the original author(s) and source are credited.

\section{References}

1. El Khamary S, Alorainy IA (2006) Case 100: spinal epidural meningioma. Radiology 241:614-617

2. Jaiswal A, Shetty AP, Rajasekaran S (2008) Giant cystic intradural schwannoma in the lumbosacral region: a case report. J Orthop Surg (Hong Kong) 16:102-106

3. Koeller KK, Rosenblum RS, Morrison AL (2000) Neoplasms of the spinal cord and filum terminale: radiologic-pathologic correlation. Radiographics 20:1721-1749 
4. Kumar R, Guinto FC Jr, Madewell JE, Swischuk LF, David R (1988) The vertebral body: radiographic configurations in various congenital and acquired disorders. Radiographics 8:455-485

5. Liu JK, Cole CD, Kan P, Schmidt MH (2007) Spinal extradural arachnoid cysts: clinical, radiological, and surgical features. Neurosurg Focus 22:E6

6. Patel U, Pinto RS, Miller DC, Handler MS, Rorke LB, Epstein FJ et al (1998) MR of spinal cord ganglioglioma. Am J Neuroradiol 19:879-887

7. Tabaddor K, Lamorgese JR (1975) Lumbar epidermoid cyst following single spinal puncture: case report. J Bone Joint Surg Am 57:1168-1169

8. Wakely SL (2006) The posterior vertebral scalloping sign. Radiology 239:607-609

9. Crawford AH, Parikh S, Schorry EK, Von Stein D (2007) The immature spine in type-1 neurofibromatosis. J Bone Joint Surg Am 89:123-142

10. Frazier DD, Campbell DR, Garray TA, Wiesel S, Bohlman HH, Elsment FJ (2001) Fungal infections of the spine: report of eleven patients with long-term follow-up. J Bone Joint Surg Am 83:560-565

11. Funasaki H, Winter RB, Lonstein JB, Denis F (1994) Pathophysiology of spinal deformities in neurofibromatosis. An analysis of seventy-one patients who had curves associated with dystrophic changes. J Bone Joint Surg Am 76:692-700
12. Ho NC, Hadley DW, Jain PK, Francomano CA (2002) Case 47: dural ectasia associated with Marfan syndrome. Radiology 223:767-771

13. Joseffer SS, Cooper PR (2005) Modern imaging of spinal tuberculosis. J Neurosurg Spine 2:145-150

14. Misra SN, Morgan HW (2003) Thoracolumbar spinal deformity in achondroplasia. Neurosurg Focus 14:E4

15. Winter RB, Moe JH, Bradford DS, Lonstein JE, Pedras CV, Weber AH (1979) Spine deformity in neurofibromatosis. A review of one hundred and two patients. J Bone Joint Surg Am 61:677-694

16. Berthelot JM, Maugars Y, Bertrand-Vasseur A, Lalande S, Prost A (1995) Dorsal scalloping by calcified disc herniation. Spine 20:106-107

17. Briceno CE, Fazl M, Willinsky RA, Gertzbein S (1989) Sequestrated lumbar intervertebral disc associated with vertebral erosion. Spine 14:898-899

18. Flak B, Li DK, Knickerbockes WJ (1989) Case report 567: chronic disc herniation causing bone erosion. Skeletal Radiol 18:481-482

19. Norfray JF, Gado M, Becker RL, Resnick D, Sartoris DJ (1988) Extruded nucleus pulposus causing osseous erosion of a lumbar vertebral body. A report of three cases. Spine 13:941-944

20. Vadala G, Dove R, Garbagna P (1985) Unusual osseus changes in lumbar herniated discs: CT features. J Comput Assist Tomogr 9:1045-1049 